NASA Technical Memorandum 105342

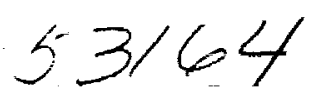

N92-13910
(NASA-TM-105342) PDWFR MANAGEMENT AND

DISTRIUUTION CONSIOERATIONS FOR A LUNAR BASE

(NASA) $9 \mathrm{P}$
CSCL O3O

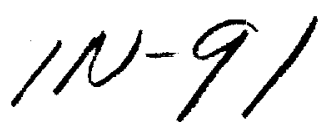

G3/91 0053164

\title{
Power Management and Distribution
}

Considerations for a Lunar Base

Barbara H. Kenny

National Aeronautics and Space Administration

Lewis Research Center

Cleveland, Ohio

and

Anthony S. Coleman

Sverdrup Technology, Inc.

Lewis Research Center Group

Brook Park, Ohio

Prepared for the

Ninth Symposium on Space Nuclear Power Systems

sponsored by the University of New Mexico

Albuquerque, New Mexico, January 12-16, 1992 


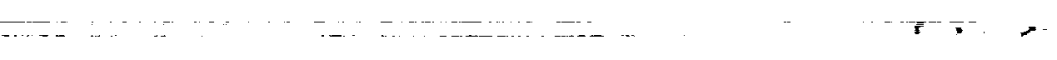




\title{
POWER MANAGEMENT AND DISTRIBUTION CONSIDERATIONS FOR A LUNAR BASE
}

\author{
Barbara H. Kenny \\ National Aeronautics and Space Administration \\ Lewis Research Center \\ Cleveland, Ohio 44135
}

\author{
Anthony S. Coleman \\ Sverdrup Technology, Inc. \\ Lewis Research Center Group \\ Brookpark, Ohio 44142
}

\begin{abstract}
This paper discusses design philosophies and technology needs for the power management and distribution (PMAD) portion of a lunar base power system. A process is described whereby mission planners may proceed from a knowledge of the PMAD functions and mission performance requirements to a definition of design options and technology needs. Current research efforts at the NASA Lewis Research Center to meet the PMAD system needs for a lunar base are described. Based on the requirements, the lunar base PMAD is seen as best being accomplished by a utility like system, although with some additional demands including autonomous operation and scheduling and accurate, predictive modeling during the design process.
\end{abstract}

\section{INTRODUCTION}

The power management and distribution (PMAD) portion of any power system performs critical, yet subtle tasks. It takes the power from the source, conditions it as necessary, and moves it to the load reliably and safely. Its exact form is very much dependent on interfaces with other subsystems. What form is the output source power? How much power is to be transported? What level of reliability and quality is required by the user? These and many other detailed questions must be answered before the PMAD subsystem can be designed.

During the mission planning phase, it is difficult to discuss possible PMAD designs because the detailed requirements and subsystem interfaces are not known. This is the current situation with the lunar base: only general requirements have been developed. These general requirements must be used to define the performance of the lunar PMAD system so possible designs and technology needs can be considered. One way to do this is to first define the functions of the PMAD system, then consider the requirements the system must meet, then determine the implications of the requirements on the PMAD functions. Once the performance of the PMAD functions has been determined, possible designs and associated technology needs can be discussed.

Observations of the Space Station Freedom (SSF) PMAD functions and requirements can be used to help define the PMAD performance for the lunar base. The SSF has a large distributed power system with many users, a long life, and the capacity for future growth. We believe the lunar base power system will have many similar characteristics but with added challenges including: higher power levels, higher launch costs, larger physical size, longer eclipse periods, longer base to ground communication times, and a harsher operating environment.

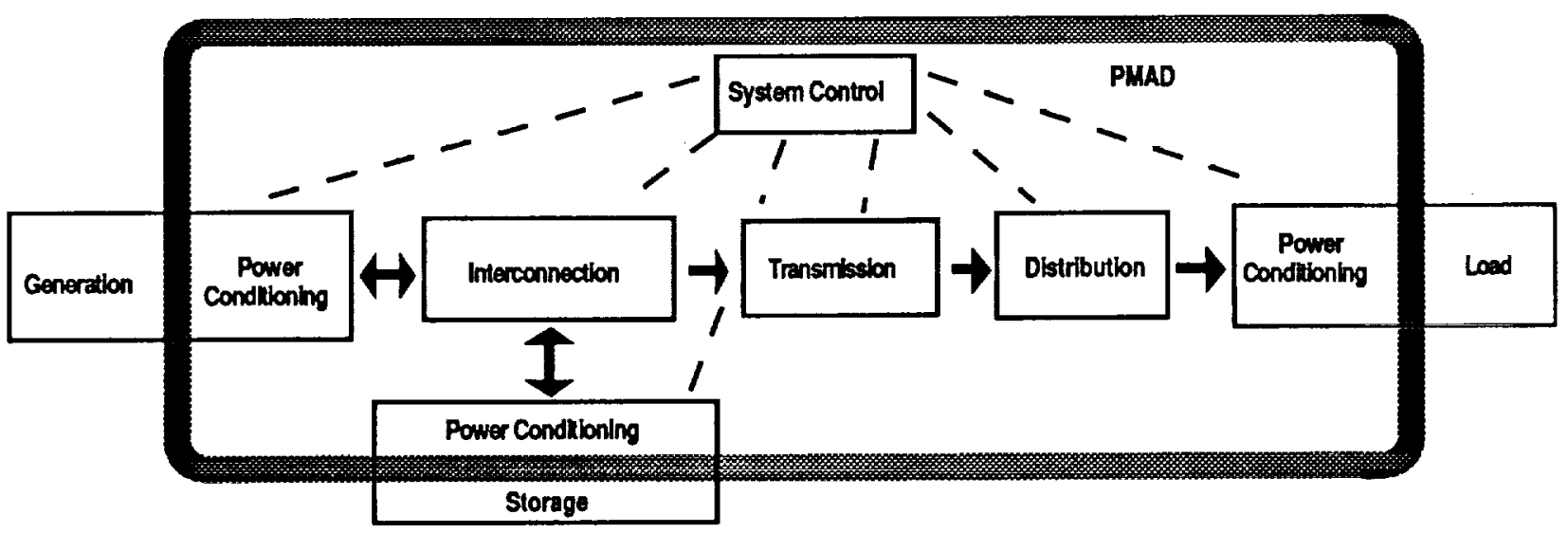

FIGURE 1. Block Diagram of PMAD Functions. 


\section{PMAD FUNCTIONS}

The PMAD system is responsible for delivering the power from the source and storage devices to the loads. This requires several functions as seen in Figure 1 and explained in Table 1. These functions were previously derived by Kenny et al. (1990) based on a utility-type system such as the Space Station Freedom. However, these functions could be used to describe all space PMAD systems by varying the extent to which each function is performed. For example, in smaller spacecraft, the transmission portion would not be very complex since the source is close to the load and the power being moved is small. On the lunar base, however, there will be a significant transmission function because the source and loads may be separated by kilometers with hundreds of kilowatts to transfer.

TABLE 1. Description of PMAD Functions.

\begin{tabular}{|c|c|}
\hline GenericPMAD Function: & Deactiotion \\
\hline Source Power Conditioning and Control & $\begin{array}{l}\text { Regulates the source electrical output and converts it into a form desired for } \\
\text { transmission }\end{array}$ \\
\hline Storage Power Conditioning and Control & Converts and controls the storage electrical input and output to the required values \\
\hline Interconnections & $\begin{array}{l}\text { Allows different source and source/storage combinations to be connected to the main } \\
\text { bus or transmission system }\end{array}$ \\
\hline Transmission & Transports the power from the source to a "load center". May be at higher voltage \\
\hline Distribution & $\begin{array}{l}\text { Transports the power at a lower voltage from or within a load center to the user } \\
\text { interfaces }\end{array}$ \\
\hline Load Power Conditioning and Control & $\begin{array}{l}\text { Converts the power to a form and quality required by the user (this function is otten } \\
\text { performed by the user) }\end{array}$ \\
\hline System Health Monitoring and Control & $\begin{array}{l}\text { Monitors and controls the overall system including fault detection, isolation, } \\
\text { recovery, and repair, and may also include load scheduling on larger systems }\end{array}$ \\
\hline
\end{tabular}

\section{REOUIREMENTS}

There is a minimum set of requirements that must be known before the performance of the PMAD functions can bedefined. When the values of these requirements are known, we believe it is possible to establish the PMAD system performance to the extent that a general discussion of PMAD design possibilities can begin. Table 2 shows the minimum list of requirements and the associated lunar base values.

TABLE 2. PMAD Requirements.

\begin{tabular}{|c|c|c|}
\hline Bepuirements & Definition & Lunac Base Values \\
\hline System Relability & $\begin{array}{l}\text { Availability of power to any } \\
\text { given load }\end{array}$ & Man-raled \\
\hline "Survivability & $\begin{array}{l}\text { "Handness" to deliberate hostile } \\
\text { actions }\end{array}$ & No requirements \\
\hline Lileilme & Time system must operate & $30+$ years" \\
\hline System Salety & $\begin{array}{l}\text { Protection ol personnel, equipment, experiments, } \\
\text { environment during normal operation and failun }\end{array}$ & Man-rated \\
\hline Source Type & Energy source \& power generating method & Solar Array lor $15 t 75 \mathrm{kw}$, SP-100 with dynamic conversion for rest (Petri et. al. 1990) \\
\hline Source Size & $\begin{array}{l}\text { Amound of electrical power } \\
\text { generated by source }\end{array}$ & $25 \mathrm{kw}$ modules of solar array, $100 \mathrm{kw}$ then $450 \mathrm{kw}$ of dynamic nuclear (Petri et. al. 1990) \\
\hline Source Growth & Growth of generating capacity & Day: $25 \mathrm{kw}$ to $75 \mathrm{kw}$ to $175 \mathrm{kw}$ to $725 \mathrm{kw}$ over 101020 years (Petri et. al. 1990) \\
\hline Energy Storage & Storage for eclipse, backup, or peaking & Regenerative Fuel Cells lor the lirst $37.5 \mathrm{kw}$ (Petri of al. 1980) \\
\hline Power Quality & $\begin{array}{l}\text { Refers to tolerances of operating paramelers: } \\
\text { Irequency, volage, harmonics, elc. }\end{array}$ & Nol well delined, probably low EMI, regulated (uility like standards)" \\
\hline Size of Platiom & Distance power must be transierred & Kilometers from nuclear sources to bads, hundreds ol meters Irom solar arrays to loads \\
\hline Expected Loads & $\begin{array}{l}\text { Comparison of power required by loads } \\
\text { to power generated }\end{array}$ & Large number, diverse, lotal connected laad is much greater than source capability" \\
\hline Fexibility & Adaptability of system to new loads & Loads and load centers will change over life, In-Situ Resource Utilization plant may grow \\
\hline Environment & Where the system must operate & Must operate and be depbyed on the lunar surtace (dust, radiation, vacuum) \\
\hline
\end{tabular}


Some of the requirements presented are assumed based on anticipated similarities with the Space Station Freedom (SSF). For the lifetime requirement, the SSF is expected to be capable of operating indefinitely, although 30 years is used as a design life for life cycle cost calculations (Thomas et al. 1990). Plans for the lunar base power growth only extend 10-20 years (Petri et al. 1990), but it is reasonable to expect an indefinite life for the lunar base also.

It is important to distinguish between requirements and design solutions. Some requirements have led to such standard solutions that the design is confused with the requirement. An example is the reliability requirement. One solution often used is to make a component or function redundant to meet reliability requirements. It is not the redundancy that the system requires, but the reliability. How that reliability is achieved is a design choice; perhaps many designs would satisfy the requirements. Discriminators, such as cost or technology maturity, should determine which design is used.

Certainly, many more details of the requirements must be known to completely design the PMAD system. These requirements, however, are enough to establish the general performance of the PMAD functions. This is described in the next section.

\section{FUNCTION PEREORMANCE}

The values of the requirements in Table 2 begin to define the necessary performance of the PMAD system. A summary of the function performances resulting from the requirements is given in Table 3. By looking at the major requirements which impact function performance, one can see some general performance characteristics in each function and can begin to discuss design options. This type of analysis also shows the heavy demands placed on the PMAD functions by the lunar base requirements, more so than in previous space power systems.

Some requirements have a major impact on all the functions, some impact only a few. Lifetime, for example, impacts all the functions mainly through a maintenance or repairability feature. For the lunar base to operate indefinitely, maintenance and repair of all functions must be possible. Maintenance and repairability are new features for space systems (with the exception of the SSF). In previous space systems, where maintenance and repair were not possible, an extended operational life could be achieved by redundancy. Instead of repairing or replacing a failed component, a spare one could be used.

Environment also impacts all the functions: the PMAD system will have to operate in the dust, radiation, temperature extremes and 14 day eclipse period of the lunar surface. In addition, it will have to be constructed or deployed on the lunar surface. For the distribution function, inside one of the habitats or laboratories, construction may not be too difficult because much of the interior wiring could be accomplished prior to launch. But for the functions occurring on the surface, such as the transmission, deployment and construction will have to occur at the site. Any necessary tools to deploy the equipment must be considered as part of a proposed design. Again, this is an unusual requirement for space systems; most are integrated and assembled before being launched.

Other requirements, on the other hand, do not impact all of the functions. The "expected loads" requirement, for example, impacts only the distribution and control functions of the PMAD system. The distribution system must be designed to provide power to a multitude of loads, and the health monitoring and control system must allow the users to efficiently share the available power. Except for Space Station Freedom, a space power system with many more connected loads than available source power is also unusual (Kenny et al. 1990). Typical satellite systems have loads that essentially match the available sounce power.

Transmission, interconnection, and distribution are functions accomplished through a system architecture. Requirements that impact architecture decisions are system reliability, system growth, and flexibility. For reliability, the architecture must provide alternate means of moving power from the sources to the loads. For growth and flexibility, the architecture must handle new sources coming on line and changes in power requirements of loads and load centers.

There can be many arguments about the details of Table 3 and the extent to which each requirement impacts a given function. We present it as a tool to help define the PMAD system performance at this early stage in planning for lunar mission. Design options and technology challenges can now be discussed in light of the function performances identified. 
TABLE 3. Required Function Performances.

\begin{tabular}{|c|c|c|}
\hline Eunction & $\begin{array}{l}\text { Primankequinements thet } \\
\text { Delemine Periomance }\end{array}$ & Bequred Function Portomance \\
\hline \multirow{6}{*}{ cource power condlioning } & LHetmo & Must be maintainable \\
\hline & System Sefay & Protection isolation of source and system during fault conditions \\
\hline & Source Type & Control of source's output amount and torm (voltage, frequency) \\
\hline & Sounce Sbe & Appropriale size of power conditioning equipment \\
\hline & Power quality & Converts source ou put power into transmission form within blerances \\
\hline & Enironment & Must be tolerant of lunar conditions such as dust radiation, and temperature extremes \\
\hline \multirow{9}{*}{ Interconnection } & System Reliability & Must interconnect sources 8 storage so if one tails, others are available \\
\hline & Lffotme & Maintainable and flexible, able to connect to new sources \& storage devices \\
\hline & System Suldy & Failure of one interconnected device does not affect other devices or the system \\
\hline & Source Type & Must connect different sources, or diferent types of sources, with stability \\
\hline & Source Stze & Appropriate size of switchgear, cables, etc \\
\hline & Source Growh & Must accomodate additional sources while maintaining stability \\
\hline & Energy Storage & Fuel colls and electrolyzers must be ted into transmission system \\
\hline & Floxibility & Must be flexible to hande rerouting of power (if new load center is built) \\
\hline & Environment & Must be tolerant of lunar conditions such as dust, radiation, and temperature extremes \\
\hline \multirow{5}{*}{ storage power conditioning } & Llfotime & Must be maintainable \\
\hline & System Sofdy & Protection/ isolation of hel cell, electrolyzer, and system during fault conditions \\
\hline & Energy Storage & Fuel cell output and electrolyzer input interfaced to transmission system \\
\hline & Power quality & Fuel cell and electrolyzer interfaces do not cause out of blerance distortions \\
\hline & Envronment & Must be tolerant of lunar conditions such as dust, radiation, and temperature extremes \\
\hline \multirow{10}{*}{ trensmisetion } & System Reliabilly & Architecture must allow different avenues of routing power \\
\hline & Lifetime & Ability to reroute power for maintenance or new load centers, maintainable \\
\hline & System Seldy & Must not interfere with surface activities or personnel \\
\hline & Source Type & Consideration of transmission voltage \& frequency depending on source output \\
\hline & Source Size & Appropriate size of switchgear and cables \\
\hline & Source Gromh & Must be designed to handle extra power \\
\hline & Power quality & Low noise system, must nol radiate or receive outside noise \\
\hline & Size of Platiorm & Must transmit power to distribution points \\
\hline & Flexibility & Must have capability to reroute power \\
\hline & Environment & Must be tolerant of lunar conditions and not interfere with surface activities \\
\hline \multirow{7}{*}{ distribution } & System Reliability & Architecture must allow different avenues of routing power \\
\hline & Lifetime & Ability to reroute power for maintenance or new loads, maintainable \\
\hline & System Saloty & Protection of personnel and equipment during fault conditions \\
\hline & Power qually & Low noise system, must not radiate or recelve outside noise \\
\hline & Expected Loads & Loads must share power \\
\hline & Flaxibility & Ability to deliver to different types \& sizes of loads \\
\hline & Environment & Less impact if located "indoors", but musi tolerate possible depressurization \\
\hline \multirow{4}{*}{ load power conditioning } & LHalme & Must be maintainable \\
\hline & System Sadety & Provection/isolation of experiments and loads \\
\hline & Power qually & Must not put noise/harmonics back on the distribution system \\
\hline & Environment & Less impact if located "indoors", but must bolerate possible depressurization \\
\hline \multirow{12}{*}{$\begin{array}{l}\text { system healh } \\
\text { monitoring } \& \text { control }\end{array}$} & System Reliability & Must be able b detect faults, possibly incipient ones, \& direct rerouting of power \\
\hline & Lifalime & Fault detection, isolation, recovery \& repair, self-healing \\
\hline & System Salchy & Power system continues to operate safely and reliably during control system failure \\
\hline & Sounce Type & Monitors source outputs, reacts if oul of tolerances (reconfigures or disconnects) \\
\hline & Source Stro & Must monitor available power \\
\hline & Source Growth & Must monitor increased number of sources \& schedule increased available power \\
\hline & Energy Storage & Fuel cell and electrolyzer monitored, energy storage \& release controlled \\
\hline & Power qually & Measures parameters \& flags problems \\
\hline & Slze of Plation & Health monitoring and control distributed over the base \\
\hline & Expected Laeds & Must measure many loads' power usage, must have proirity list of loads \\
\hline & Floxibility & Must be able to adjust voltage \& current out of blerance trip points \\
\hline & Environment & Must be tolerant of lunar conditions such as dust, radiation, and temperature extremes \\
\hline
\end{tabular}




\section{DESIGN OPTIONS}

In addition to performing all the functions as described in Table 3, the lunar base PMAD design must provide a low system mass. The cost to launch payload to the lunar surface is currently estimated to be between $\$ 80,000 / \mathrm{kg}$ and $\$ 100,000 / \mathrm{kg}$ which is approximately ten times the cost to launch to low earth orbit (Brandhorst 1988). The system mass must therefore be an important consideration in the proposed designs. However, the lowest PMAD mass does not necessarily imply the lowest system mass. If more mass in the PMAD subsystem leads to a more efficient delivery and use of power, that means less power must be generated at the source, and less energy must be radiated away as heat. Thus the PMAD design with the lowest system mass may not be the PMAD design with the lowest PMAD mass.

With the exception of low mass, the terrestrial utility system has been successfully meeting many similar requirements for almost one hundred years. The terrestrial electric utility system is a good analog for an initial design of a lunar PMAD system (Bercaw 1989). It is very reliable; it moves large amounts of power; it accommodates growth; power is available at many locations; and there are many loads on the system.

The terrestrial utility system meets its requirements through a grid of paralleled sources and loads. By paralleling the sources, the system pools its resources onto a power grid. This power can then be used wherever needed. The amount of power taken from the grid is not limited by the size of any one generating station, only by the size of the conductors and switchgear moving the power to the load. The loads can change and grow to the limit of the conductors and switchgear provided. Also, this system makes a reliable network: if one generator fails, others are on line continuing to provide power to the grid.

On the lunar surface, paralleling the sources would provide similar benefits. All of the available power can be used in whatever increments are necessary, limited only by the size of conductors and switchgear to the loads. As long as the choice of the initial conductor and switchgear size is reasonable, a paralleled philosophy of PMAD design can provide a flexible backbone for later expansion and growth. Reliability can be ensured by providing alternate paths for the power through proper system architecture design.

The architecture alternative to a paralleled system is a channelized one. In this case, the power is moved in separate channels from the sources to individual groups of loads. Channelization provides the benefit that the power ratings of the protective switchgear are reduced to the maximum power surge available in the channel, not in the entire system as would be the case in a paralleled architecture. However, there are many disadvantages. Non-critical loads would need to be hard-wired onto a particular channel and would not have the flexibility of using power available on a different channel. If the load mix isn't selected correctly, one channel may be operating near capacity all the time with loads having to wait for power, while another operates at only partial capacity. Even if the load mix is selected properly, there may still be power wasted through the inability to use "left-over" power on each channel. For example, channel A may have 300 watts available and channel B may have 300 watts available, but a 500 watt load would not be able to operate. It is also more difficult to provide efficient load scheduling on several channels than on one. For these reasons, a channelized system would not allow as efficient use of power as a paralleled one.

A less efficient system will be a heavier system for the same number of loads operating and power used. The source will need to be bigger, the PMAD components will need to be sized to handle the greater amount of power being moved, and the thermal control system may be larger. With the high transportation costs to the lunar surface, every efficiency point is important to reduce system mass.

A paralleled system has some design/technology challenges, however. In the terrestrial case, a new generator coming on line joins a "stiff" system (many sources spread throughout the grid, some in "spinning reserve" status to be available for any sudden system load changes, providing essentially constant frequency and voltage) Stability is not usually an issue. This would not be accomplished as easily on the lunar surface. Various types of sources and storage devices would need to be connected together, each providing a substantial portion of the total power. Spinning reserve would be an unaffordable luxury. The interactions between the sources and storage devices would need to be studied carefully, especially with the system operating under full load. This will require close cooperation between source and storage experts and PMAD designers to design the control and interconnection functions properly.

Although the terrestrial utility system is a good starting point, the lunar base power system faces more difficult challenges. Load scheduling, and fault detection, isolation, recovery and repair must be predominantly performed 
locally and autonomously. The amount of information to send and the transmission time to send it will preclude operation by a terrestrial operator. To achieve autonomous operation, operating decisions must be made at the lowest level possible in the computer hierarchy (Nurre et al. 1991). This allows many decisions to be made simultaneously (parallel processing) instead of sequentially (as would be the case if the decisions were made centrally). This "distributed intelligence" concept requires smart components such as programmable Remote Power Controllers (RPCs) and devices with built-in test and health monitoring capability.

Autonomous load scheduling will be required to insure the most efficient use of the available power. Based on similarities with SSF, the total power requirement of the loads will exceed the capability of the source if all loads are operated at once. Some loads will be critical and must be operated all the time or whenever needed; others can be operated intermittently, as power becomes available. All the loads must share resources to maximize the use of the available power. This can be accomplished through a scheduling program. The scheduling program takes power being used by the loads throughout the system, determines what additional power is available, then commands additional loads to come on line based on their priority and required power usage.

Accurate system modeling will be required for the lunar base power system. The impact of sudden load changes and new loads on the power system must be known before reliable system operation can be ensured. This can be accomplished either through hardware, duplicating every part of the power system on a testbed, or through software, by modeling all system components, or a combination of the two. In the case of the Space Transportation System, (the Space Shuttle) there exists an exact duplicate of the electrical power system. The duplicate tests the effect of new loads on the power system. This approach would not be feasible with the lunar base because of the number of anticipated loads, sources and storage devices, and the anticipated growth and change of the base. Therefore, there must be an accurate power system model, designed and tested along with hardware development, that can predict the system effects of load switching, faults, and transients.

There are many more design implications of the required function performances of Table 3 which warrant further discussion. Some, such as high voltage transmission of power, are being considered (Schwarze 1988 and Gordon 1990). Design approaches for other issues such as operation in the hostile lunar environment, maintenance over the long life, and insurance of ultimate system reliability, need to be discussed and considered in future studies. Low mass and life cycle costs must continue to be important parameters in design decisions.

\section{Current Work}

Currently, the Electrical Component and Systems Branch at Lewis Research Center is investigating some of the issues raised in the preceding discussion. We are investigating autonomous power system operation, including fault detection, isolation, recovery and repair, and scheduling, using a testbed with a brassboard and software (Ringer et al. 1991). Built-in test capability is being researched and applied in our work with advanced motor controls (Sundberg 1990). We are in the process of setting up a small facility with distributed high frequency power to investigate different system architecture options and benefits. Differences between a channelized and paralleled architecture will be studied and quantified. Some preliminary high frequency power system modeling work is being carried out by P.C. Krause and Associates (Wasynczuk and Krause 1990). Finally, two other areas with lunar base applications are being researched: development of high temperature $\left(200^{\circ} \mathrm{C}\right.$ ) components and devices (Hammoud et al. 1991), and the complex relationship between system cost and reliability (Suich et al. 1990).

\section{CONCLUSIONS}

Power management and distribution design options should be considered as early as possible for a new mission so necessary technologies can be defined and appropriate research implemented. This is difficult to do, however, because of the integrating nature of the PMAD subsystem in the overall electrical power system and its dependance on detailed requirements. This paper addresses some very preliminary lunar base power system requirements and derives general function performances for the PMAD system. Design options based on a terrestrial utility system were suggested. Paralleled sources and loads, autonomous scheduling, distributed intelligence and accurate system modeling were discussed as design solutions that could meet the required function performances.

Research work at Lewis is focused on making some of the lunar base design options feasible. Important areas such as autonomous control, modeling, architecture selection, high temperature tolerance, and reliability are being researched. When specific requirements are finally known, our goal is to have the technology base to implement the necessary PMAD design with the lowest system mass and life-cycle cost. 


\section{Acknowledoments}

This work was accomplished at the NASA Lewis Research Center, Cleveland, Ohio under internal funding support. The authors would like to thank Robert Bercaw, Ron Cull, Irving Hansen and Gale Sundberg for their helpful comments during many reviews.

\section{References}

Bercaw, R. W. (1989) Toward an Electrical Power Utility for Space Exploration, NASA Technical Memorandum 102347, NASA Lewis Research Center, Cleveland, $\mathrm{OH}$.

Brandhorst, H. Jr. (1989) Challenges for Future Space Power Systems, NASA Technical Memorandum 102063, NASA Lewis Research Center, Cleveland, $\mathrm{OH}$.

Gordon, L. B. (1990) Electrical Transmission on the Lunar Surface-- Part I DC Transmission, Interim Report under NASA Grant \# NASA-NAG-3-1055, Space Power Institute, Auburn University, AL.

Hammoud, A. N., E. D. Baumann, I. T. Myers, and E. Overton (1991) "High Temperature Power Electronics for Space" in Transactions, First International High Temperature Electronics Conference, Albuquerque, N.M., 16-20 June 1991, pp 11-16.

Kenny, B. H., R. C. Cull, and M. D. Kankam, (1990) "An Analysis of Space Power System Masses," in Proceedings of the 25th Intersociety Energy Conversion Engineering Conference, Volume 1, pp 484-489.

Nurre, J.H., B.H. Kenny, and J.A. Kish (1991) "A Review of Autonomous Power System Control for the Lunar Base Station," in The Proceedings of the 23rd Annual North American Power Symposium held in Carbondal, IL, 7-8 October 1991.

Petri, D. A., R. L. Cataldo, and J. M. Bozek (1990) "Power System Requirements and Definition for Lunar and Mars Outposts" in Proceedings of the 25th Intersociety Energy Conversion Engineering Conference, Volume 1, pp 18-27.

Ringer, M. J., T. M. Quinn, and A. Merolla (1991) "Autonomous Power System Intelligent Diagnosis and Control" The Proceedings of the 1991 NASA Goddard Space Applications of Artifical Intelligence Conference held in Greenbelt, Md, 13-15 May 1991.

Schwarze, G. (1988) "Space Power Radiation Cooled DC Transmission Line Analysis" in Transactions Fifth Symposium on Space Nuclear Power Systems, CONF 880122-- Summs., Albuquerque, N.M., 11-14 January 1988.

Sundberg, G. (1990) "Advanced Launch System (ALS): Electrical Actuation and Power Systems Improve Operability and Cost Picture" in Proceedings of the IEEE 1990 National Aerospace and Electronics Conference NAECON 1990, Volume 3, pp 1346-1350.

Thomas, R. L., and G. J. Hallinan (1990) "Design of the Space Station Freedom Power System" in IEEE Aerospace and Electronic Systems Magazine, Volume 5, Number 1, pp. 19-24.

Wasynczuk, O. and P. C. Krause (1990) "Simulation and Dynamic Performance of a $20 \mathrm{kHz}$ Spacecraft Power System" in Proceedings of the IEEE 1990 National Aerospace and Electronics Conference NAECON 1990, Volume 1, pp 343-347. 
Public reporting burden lof this collection of information is estimaled 10 average 1 hour per response, including the time lor reviewing lnatruclions, searching existing datu sources, Public reporting burden tor this collection of and completing and reviewing the collection of intomation. Send comments regarding this burden estimate or any other aspect of this

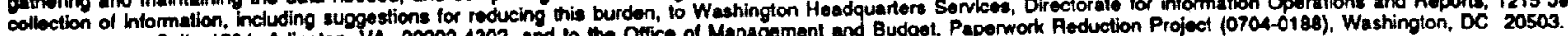
Devis Highway Sult 1204, Arlington, VA 22002-4302, and to the Otice of Management and Budgot, Paperwork Aeduction Project (OrOa-O180), Washing \begin{tabular}{l|l} 
1. AGENCY USE ONLY (Leave blank) & 2. REPORT DATE
\end{tabular}

\begin{tabular}{|r|r|}
\hline 1. AQENCY USE ONLY (Leavoblank & 1991 \\
\hline
\end{tabular}
3. REPORT TYPE AND DATES COVERED

\section{TITLE ANO SUBTITLE}

Power Management and Distribution Considerations for a Lunar Base

5. FUNDING NUMBERS

Barbara H. Kenny and Anthony S. Coleman

7. PERFORMING ORGANIZATION NAME(S) AND ADDRESS(ES)

6. PERFormina organization REPORT NUMBER

National Aeronautics and Space Administration

Lewis Research Center

$E-6710$

Cleveland, Ohio 44135-3191

9. SPONSORING/MONITORINO AGENCY NAMES(S) AND ADDRESS(ES)

10. SPONSORING/MONITORING AGENCY REPORT NUMBER

National Aeronautics and Space Administration

Washington, D.C. 20546-0001

NASA TM -105342

11. SUPPLEMENTAAY NOTES

Prepared for the Ninth Symposium on Space Nuclear Power Systems sponsored by the University of New Mexico, Albuquerque, New Mexico, January 12-16, 1992. Barbara H. Kenny, NASA Lewis Research Center; Anthony S. Coleman, Sverdrup Technology, Inc., Lewis Research Center Group, 2001 Aerospace Parkway, Brook Park, Ohio 44142. Responsible person, Barbara H. Kenny, (216) 433-6289.

12.. DISTRIBUTION/AVAILABILITY STATEMENT

12b. OISTRIBUTION CODE

Unclassified - Unlimited

Subject Category 91

\section{ABSTRACT (Max/mum 200 words)}

This paper discusses design philosophies and technology needs for the power management and distribution (PMAD) portion of a lunar base power system. A process is described whereby mission planners may proceed from a knowledge of the PMAD functions and mission performance requirements to a definition of design options and technology needs. Current research efforts at the NASA Lewis Research Center to meet the PMAD system needs for a lunar base are described. Based on the requirements, the lunar base PMAD is seen as best being accomplished by a utility like system, although with some additional demands including autonomous operation and scheduling and accurate, predictive modeling during the design process.

\section{SUBJECT TERMS}

Power management and distribution; Lunar base; Requirements

17. SECURTY CLASSIFICATION
OF REPORT
Unclassified

18. SECURITY CLASSIFICATION
OF THIS PAGE
Unclassified

Unclassified
19. SECURITY CLASSIFICATION OF ABSTRACT

Unclassified
15. NUMBER OF PAQES

8

16. PRICE CODE

$\mathrm{AO} 2$
20. LIMITATION OF ABSTRACT 